Original Paper

\title{
miR-494 Sensitizes Gastric Cancer Cells to TRAIL Treatment Through Downregulation of Survivin
}

\author{
Shuning $\mathrm{Xu}^{\mathrm{a}}$ Danyang $\mathrm{Li}^{\mathrm{a}} \quad{\text { Tianyuan } \mathrm{Li}^{\mathrm{a}}}^{\mathrm{L}}$ Lei Qiao $\mathrm{Ke} \mathrm{Li}^{\mathrm{a}} \quad$ Leiming Guo \\ Ying Liu $^{\mathrm{a}}$ \\ aDepartment of Internal Medicine, Affiliated Tumor Hospital of Zhengzhou University, Zhengzhou,

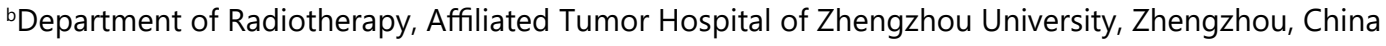

\section{Key Words}

Trail • miR-494 • Gastric cancer • Survivin

\begin{abstract}
Background/Aims: TNF-related apoptosis-inducing ligand (TRAIL) is a novel and low-toxic anti-tumor drug used for various cancers. However, cancer cells usually develop mechanisms to acquire the resistance against TRAIL. Among these changes, dysregulation of microRNAs (miRNAs) usually occurs in cancer cells and is responsible for induction of drug resistance. Methods: Expression of miR-494 in gastric cancer tissues and cell lines was detected by quantitative reverse transcriptase real time PCR (qRT-PCR) analysis. Effect of miR-494 on regulating the TRAIL sensitivity to gastric cancer cell lines was evaluated by MTT assays. Bioinformatics and luciferase reporter assays were used to confirm the regulation of miR494 on survivin. Mitochondrial apoptosis pathway in gastric cancer cells was tested by western blot and flow cytometry analysis. Results: Obvious downregulation of miR-494 was observed in gastric cancer cells. Furthermore, we found that expression profile of miR-494 was associated with TRAIL-sensitivity in gastric cancer. Enforced expression of miR-494 was found to sensitize the gastric cancer cells to TRAIL-induced cytotoxicity. Mechanically, Luciferase reporter assays proved that survivin was the target of miR-494 in gastric cancer cells. Enforced expression of miR-494 decreased the expression of survivin, and thus promoted the TRAILinduced mitochondria collapse and apoptosis pathway. Conclusion: MiR-494/survivin axis represents a potential mechanism which is responsible for TRAIL resistance in gastric cancer cells. Increasing the miR-494 expression may serve as a novel therapeutic strategy to sensitize gastric cancer cells to TRAIL treatment.
\end{abstract}




\section{Introduction}

Gastric cancer is one of the most prevalent malignant cancers worldwide. As gastric cancer patients are usually diagnosed in the advanced stages of the disease, gastric cancer represents a leading cause of cancer-related mortality worldwide [1,2]. For treatment of gastric cancer, surgery is the most effective strategy. However, for the advanced gastric cancer patients, their tumors are unresectable and the curative treatment options are limited. Systemic chemotherapy (or immunotherapy) is their only choice for the cancer treatment [3-6]. Unfortunately, cancer cells usually develop mechanisms to acquire the resistance against anti-tumor drugs [7, 8]. Given this, it's urgent to explore strategies to enhance the response of gastric cancer cells to systemic treatment.

TNF-related apoptosis-inducing ligand (TRAIL) is an important member belonged to the TNF superfamily. In TRAIL-dependent pathway, TRAIL binds to death receptor 4 (DR4) and death receptor 5 (DR5) followed by recruitment of procaspase- 8 to form the deathinducing signaling complex (DISC). Subsequently, caspase-8 was activated and mitochondrial apoptosis occurs [9-11]. As TRAIL-induced cytotoxicity shows high specificity to cancer cells, it is considered as a novel and low-toxic anti-tumor drug used for various cancers [12, 13]. However, previous research indicated that gastric cancer cells usually showed tolerance to TRAIL-induced apoptosis $[14,15]$. Therefore, increasing the sensitivity of gastric cancer cells to TRAIL treatment is meaningful for the cancer patients.

MicroRNAs (miRNAs) are endogenous and single-stranded RNAs with length of approximate 20-24 nucleotides. Studies have indicated that miRNAs regulate most of basal progress such as cell cycle, survival, differentiation and apoptosis, because miRNAs induce mRNA degradation by binding to the 3'-untranslated region (3'-UTR) of targeted mRNAs [1618]. However, expression of miRNAs is usually dysregulated in cancer cells. Accumulating evidence has demonstrated that aberrant miRNAs expression profile is responsible for cancer proliferation, metastasis and drug resistance $[19,20]$. Moreover, it has been reported that dysregulation of miRNAs induces obvious resistance to TRAIL in some cancers [21, 22]. The aim of this study is focused on the effect of miR-494 on regulating the TRAIL sensitivity to gastric cancer.

\section{Materials and Methods}

\section{Cell lines and patients' specimens}

Human gastric cancer cell lines BGC-823 and MGC-803 were obtained from the China Centre for Type Culture Collection (CCTCC, Wuhan, China) and cultured in Dulbecco's modified Eagle's medium (DMEM, Invitrogen, Carlsbad, CA, USA) supplemented with $10 \%$ fetal calf serum. Cells were cultured in humidified atmosphere containing 5\% CO2 at $37^{\circ} \mathrm{C}$. For detection of miR-494 in vivo, tumor tissues and their corresponding paracancerous tissues derived from 30 primary gastric cancer patients were collected at Affiliated Tumor Hospital of Zhengzhou University between may 2016 and September 2017. The median age of the patients was 59 years (range, 39-83 years). We obtained informed consent from all of them. The experimental protocols were approved by the ethics committee of Affiliated Tumor Hospital of Zhengzhou University.

\section{Transfection}

Mature human miR-494 mimics (5'-UGAAACAUACACGGGAAACCUCUU-3') and negative control oligonucleotides (NCO, 5'-CUCAGAAUACAGAUUGACACGCUA-3') were purchased from GenePharma Co. Ltd. (Shanghai, China). For Knockdown of survivin, its specific siRNA was purchased from Santa Cruze Biotechnology (sc-29499). For enforced expression of survivin, open reading frame of survivin gene was amplified and inserted into the pcDNA3.1 eukaryotic expression plasmid (Invitrogen). Cells were transfected with miR-494 mimics (50 pmol/ml), NCO (50 pmol/ml), survivin siRNA (50 pmol/ml) and survivin plasmid $(2 \mu \mathrm{g} / \mathrm{ml})$ by using Lipofectamine 2000 (Invitrogen) according to the manufacturer's instruction. 


\section{Cellular Physiology Cell Physiol Biochem 2018;51:2212-2223 \begin{tabular}{l|l|l} 
and Biochemistry Published online: 7 December 2018 & $\begin{array}{l}\text { (c) } 2018 \text { The Author(s). Published by S. Karger AG, Basel } \\
\text { www.karger.com/cpb }\end{array}$
\end{tabular}}

Xu et al.: miR-494 Sensitizes Gastric Cancer to TRAIL

\section{Cell viability assay}

Transfected cells were seeded into 96 -well plates at a density of $5 \times 10^{3}$ cell $/$ well. After cellular adhesion, culture medium containing TRAIL was added to each well. $48 \mathrm{~h}$ after incubation, 3-(4, 5-dimethylthiazol2-yl)-2, 5-diphenyltetrazolium bromide (MTT, Sigma-Aldrich, Germany) reagent (100 $\mu \mathrm{L}$ medium +20 $\mu \mathrm{L}$ MTT solution) was added to each well for $4 \mathrm{~h}$ incubation. After the cells were suspended in $150 \mu \mathrm{L}$ of dimethyl sulfoxide (DMSO), the absorbance of each well at $570 \mathrm{~nm}$ was read on a spectrophotometer. The half maximal inhibitory concentration (IC50) was calculated according to the cell viability curve.

\section{Reverse transcription-quantitative polymerase chain reaction (RT-qPCR)}

Relative expression of miR-494 was detected according to the quantitative real-time polymerase chain reaction (qRT-PCR) assays. Briefly, total RNAs from cell lines and patients' tissues were extracted by TRIzol reagent (Invitrogen) and reversely transcribed by One Step PrimeScript miRNA cDNA Synthesis Kit (TaKaRa, China) according to the manufacturer's instruction. MiR-494 expression levels were measured by SYBR Premix Ex Taq (TaKaRa) on the Applied Biosystems 7500 Sequence Detection system (Applied Biosystems, USA). MiR-494 primer sequence is as follows: 5'-TGAAACATACACGGGAAACCTCTT-3'. Relative expression of miR-494 was normalized to U6 snRNA according to the the $2^{-\triangle \triangle \mathrm{Cq}}$ method [23].

\section{Immunoprecipitation}

Cells were lysed in RIPA buffer (Cell Signaling Technology, USA) followed by incubation with primary antibodies overnight at $4^{\circ} \mathrm{C}$. Protein A agarose beads were then supplemented into the cell lysate and maintained for $2 \mathrm{~h}$. After centrifugation, the resulting beads were mixed with the SDS loading buffer and boiled at $95^{\circ} \mathrm{C}$ for 5 mins for preparation of following western blot analysis.

\section{Western blot analysis}

Equal amounts of protein from each sample were separated by $10 \%$ SDS-PAGE, and then transferred to a nitrocellulose membrane. Next, the membranes were blocked in 5\% skimmed milk and probed with primary antibodies of survivin, DR4, DR5, cytochrome c, apoptosis inducing factor (AIF), apoptotic protease activating factor-1 (Apaf-1), caspase-9, caspase-8, caspase-3 and glyceraldehyde-3-phosphate dehydrogenase (GAPDH). Subsequently, proteins on the membranes were probed with HRP-conjugated secondary antibodies, and then visualized by using enhanced chemiluminescent substrate (Thermo Fisher Scientific, Inc, USA). In addition, cellular mitochondria were separated by using Mitochondria / Cytosol Fraction Kit (BioVision, USA) according to the manufacturer's instruction. The remaining cell lysate was used as the cytoplasm fraction.

\section{Luciferase reporter assay}

Survivin 3' UTR containing predicted miR-494 binding sites and corresponding mutant sites was cloned into the pMIR-firefly luciferase reporters (Invitrogen). The mutant survivin reporter was created by mutating the seed region of the miR-494 binding site (AUGUUUCA) by using the site-directed mutagenesis kit (Takara, Dalian, China). pMIR-firefly luciferase reporters, pRL-TK renilla plasmids (Promega, USA) and miR-494 mimics (or NCO) were co-transfected into cells by using Lipofectamine $2000.48 \mathrm{~h}$ later, luciferase activities were measured by using Dual Luciferase Assay System (Promega) according to the manufacturer's instruction.

\section{Flow cytometry}

Cells were plated on 6-well plates with $2 \mathrm{ml} \mathrm{RPMI-1640} \mathrm{medium.} \mathrm{Then,} \mathrm{cells} \mathrm{were} \mathrm{transfected} \mathrm{with}$ RNAs followed by treatment with $50 \mathrm{ng} / \mathrm{ml}$ TRAIL for $48 \mathrm{~h}$. After incubation, cells were collected and analyzed by flow cytometry (Becton Dickinson, USA). For detection of DR4 and DR5 on cell surface, BGC-823 and MGC-803 cells were incubated with anti-DR4-PE and anti-DR5-PE (R\&D System, USA) before analysis on flow cytometry. For detection of mitochondrial membrane potential, cells were incubated with $5 \mu \mathrm{M}$ JC-1 (Molecular Probes, USA) before analysis on flow cytometry. For measurement of apoptotic rate, cells were stained with PI and Annexin V (Sigma-Aldrich, USA) for $20 \mathrm{~min}$ at room temperature. Subsequently, percentage of apoptotic cells was quantified by using the flow cytometry. 


\section{Cellular Physiology Cell Physiol Biochem 2018;51:2212-2223 \begin{tabular}{l|l|l} 
and Biochemistry Published onlIne: 7 December 2018 & $\begin{array}{l}\text { (c) } 2018 \text { The Author(s). Published by S. Karger AG, Basel } \\
\text { www.karger.com/cpb }\end{array}$ \\
\hline
\end{tabular}

\section{In vivo tumorigenesis assays}

MiR-494-overexpressed BGC-823 cells were conducted to stably express miR-494 by using a lentiviralbased system (Genechem Co., Ltd., Shanghai, China) for tumourigenesis assays. Xenograft tumors were generated via the subcutaneous injection of miR-494-overexpressed BGC-823 (LV-miR-494) or control BGC823 (LV-control) into the 4 week-old BALB/c nude mice $\left(5 \times 10^{6}\right.$ cells per mouse). After xenografts reached $0.5 \mathrm{~cm}$ in diameter, animals were treated with TRAIL i. p. twice a week (50 $\mathrm{gg} / \mathrm{kg})$ until the mice were killed 28 days post-injection. The animal care and experimental protocols were approved by the Animal Care Committee of Affiliated Tumor Hospital of Zhengzhou University.

\section{Statistical analysis}

Data were obtained from at least three independent experiments and presented as mean \pm standard deviation (SD). Statistical analysis was performed by using SPSS 15.0 software. For comparison analysis, two-tailed Student's t-tests were used to estimate the statistical differences between two groups. One-way analysis of variance (ANOVA) and Bonferroni's post hoc test were used to determine the differences between three or more groups. Differences were considered significant when the values of $P<0.05$.

\section{Results}

\section{Downregulation of miR-494 in gastric cancer}

To study the potential role of miR-494 in gastric cancer, we collected some clinical samples for analysis of qRT-PCR. The results showed that gastric cancer tumor tissues expressed obviously lower levels of miR-494 compared to their corresponding paracancerous tissues (Fig. 1A). Furthermore, we also observed significant decrease of miR-494 expression in gastric cancer cell lines in vitro (Fig. 1B). These results suggested that miR-494 was a potential tumor suppressor in gastric cancer.

Enforced expression of miR-494 sensitized gastric cancer cells to TRAIL-induced cytotoxicity

As the miR-494 was downregulated in gastric cancer cells, we corrected this disorder of miR-494 by transfection with miR-494 mimics in BGC-823 and MGC-803 gastric cancer cell lines. The transfection efficiency of miR-494 mimics in BGC-823 and MGC-803 was shown in Fig. 2A. We then found that enforced expression of miR-494 in these gastric cancer cells significantly enhanced the cytotoxicity of TRAIL to BGC-823 and MGC-803 gastric cancer cells (Fig. 2B). Intuitively, we showed that miR-494 treatment was able to decrease the IC50 of TRAIL to both BGC-823 and MGC-803 gastric cancer cells (Fig. 2C). We therefore demonstrated that miR-494 can be used as a potential sensitizer to increase the TRAILinduced cytotoxicity against gastric cancer. In addition, we chose the concentration of $50 \mathrm{ng} /$ $\mathrm{ml}$ TRAIL for combination treatment with miR-494 in the following experiments, because $50 \mathrm{ng} / \mathrm{ml}$ TRAIL single treatment induced slight cytotoxicity to BGC-823 and MGC-803 cells.

Fig. 1. Downregulation of miR-494 in gastric cancer. A: Expression of miR-494 in gastric cancer patients' tumor tissues and paracancerous tissues $(n=30)$ was detected by qRT-PCR analysis. ${ }^{*} \mathrm{P}<0.05$ vs. normal tissues. B: QRT-PCR analysis was performed to detect the miR-494 expression in BGC and MGC-803 gastric cancer cell lines. ${ }^{*} \mathrm{P}<0.05$ vs. normal tissues.

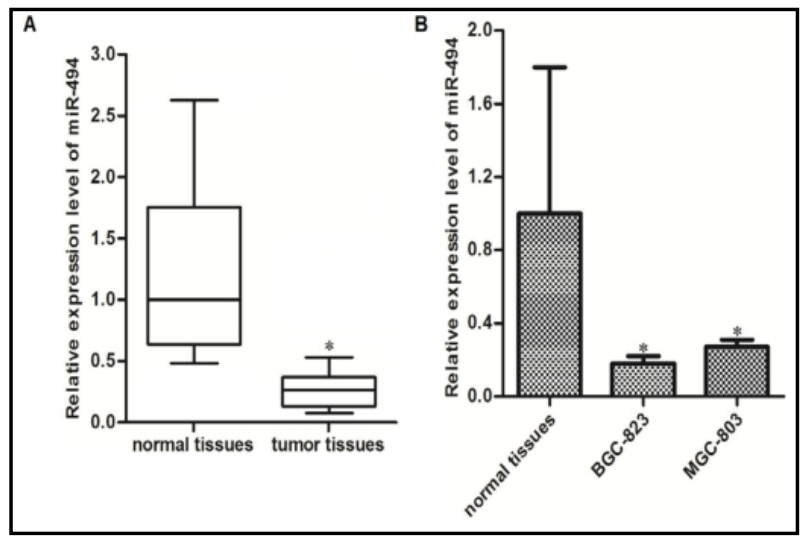


miR-494 exhibited no activity on changing the DR4/DR5 expression and distribution

Since TRAIL-triggered cell death is dependent on the activation of TRAIL-DR4/DR5 signaling [11], we next investigated whether miR-494 changed the expression of DR4 or DR5 in gastric cancer cells. However, we did not observe obvious change of DR4 or DR5 expression in BGC-823 and MGC-803 cells when they were treated with miR-494 (Fig. 3A). Furthermore, results of flow cytometry showed that miR-494 treatment can not change the

Fig. 2. Enhancement effect of miR-494 on TRAILinduced cytotoxicity against gastric cancer. A: Transfection efficiency of miR-494 mimics in BGC823 and MGC-803 cells. ${ }^{*} \mathrm{P}<0.05$ vs. NCO group. B: Transfected BGC-823 and MGC-803 cells were treated with different concentrations of TRAIL (0 250 ng/ml). Cell viability was measured by using MTT assays. ${ }^{*} \mathrm{P}<0.05$. C: The IC50 of TRAIL toward BGC-823 and MGC-803 was calculated according to the cell viability curve. ${ }^{*} \mathrm{P}<0.05$ vs. NCO group.

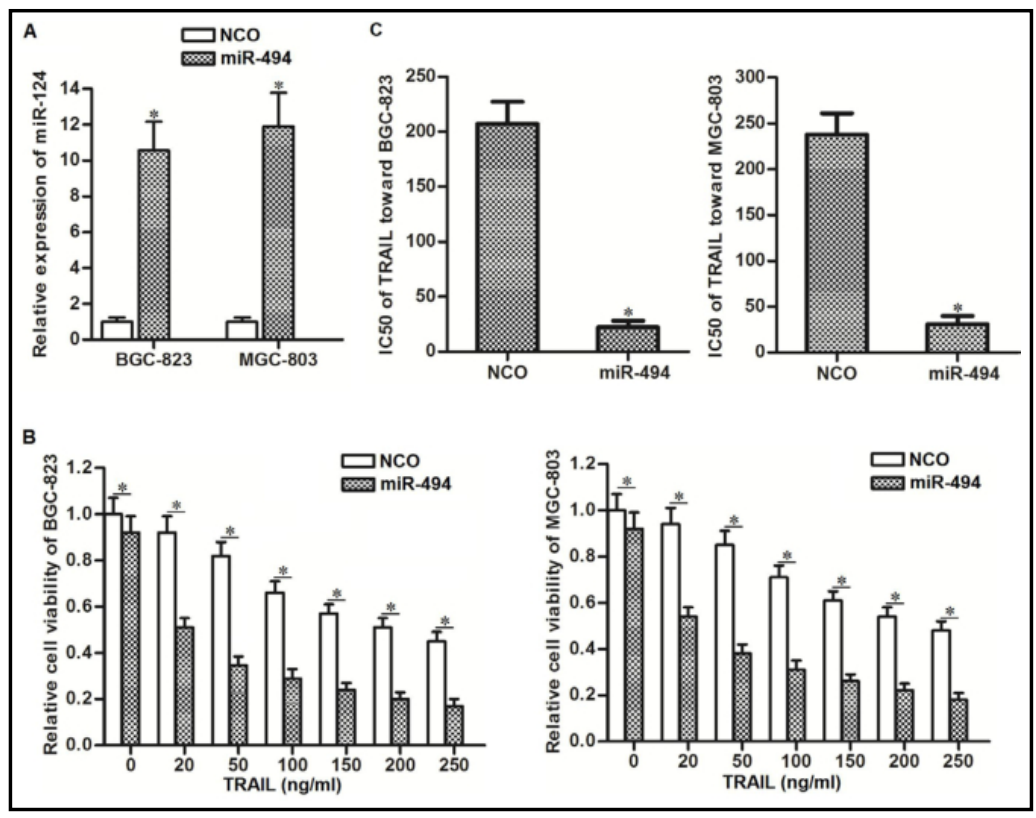

Fig. 3. MiR494 exhibited no activity on changing the DR4/ DR5 expression and distribution. A: After treatment with TRAIL (50 $\mathrm{ng} / \mathrm{ml}$ ) and miR$494 \quad(50 \mathrm{pmol} /$ $\mathrm{ml}$ ), western blot analysis was performed to detect the expression of DR4 and DR5 in BGC-823 and MGC-803 cells. B: After transfection with miR-494 (50 $\mathrm{pmol} / \mathrm{ml}$ ), flow cytometry analysis was performed to evaluate the

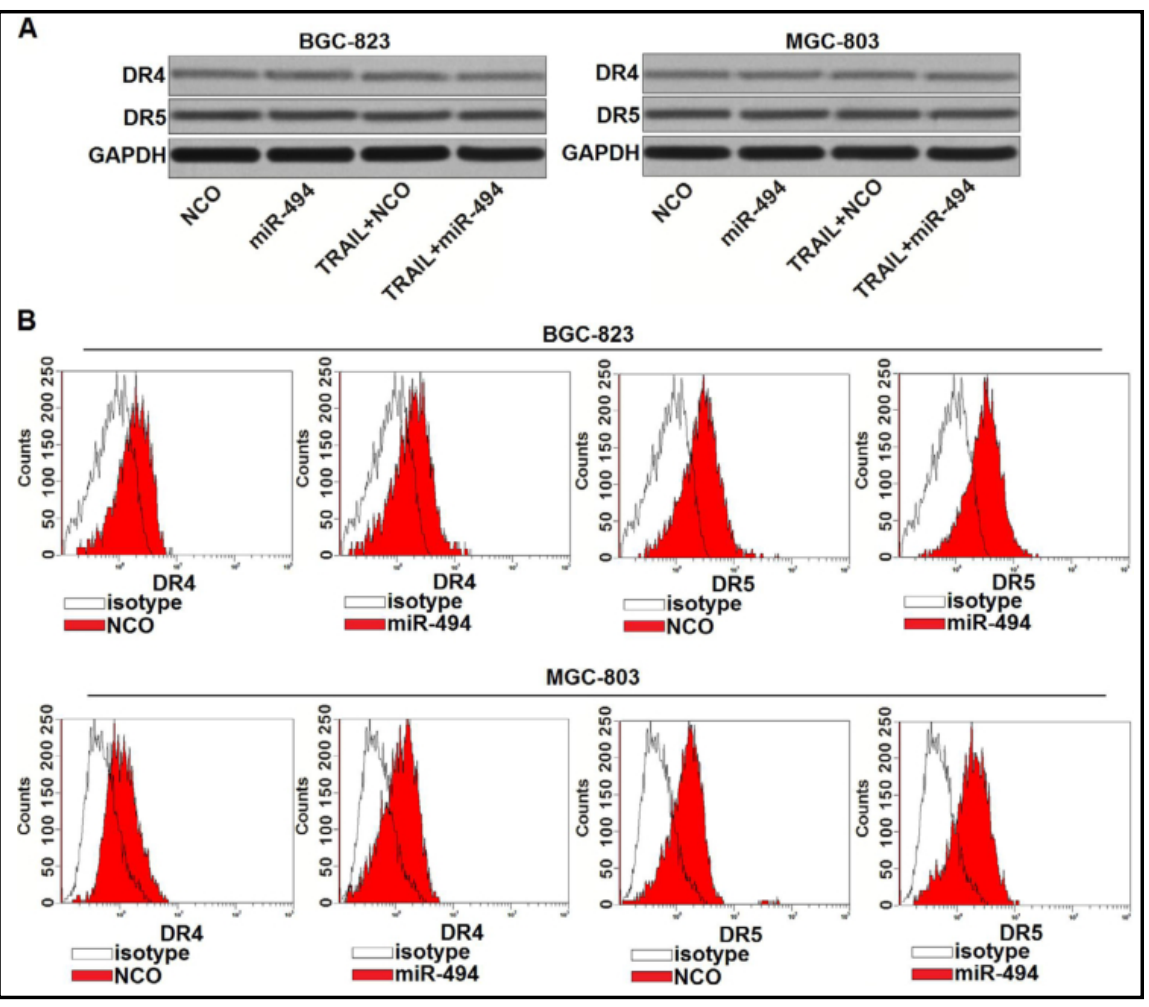
amounts of DR4 and DR5 on cell surface of BGC-823 and MGC-803 cell lines. 
amounts of DR4 and DR5 on cell surface of BGC-823 and MGC-803 gastric cancer cell lines (Fig. 3B). These results suggested that miR-494 may target the downstream of TRAIL-DR4/ DR5 pathway to sensitize the TRAIL-induced cytotoxicity to gastric cancer cells.

\section{miR-494 targets survivin in gastric cancer}

To explore the mechanism by which miR-494 sensitized TRAIL-induced cytotoxicity against gastric cancer, the public miRNA TargetScan database (www.targetscan.org) as well as miRanda database (http://www.microrna.org/) were used to predict the potential target of miR-494. Survivin, a member of the inhibitor of apoptosis protein (IAP) family [24] was found to contain putative binding site paired with miR-494 (Fig. 4A). Furthermore, in contrast to the downregulation of miR-494 in BGC-823 and MGC-803 cell lines (Fig. 1B), expression of survivin was increased in these gastric cancer cells (Fig. 4B). As survivin was reported to contribute to TRAIL resistance in some cancers $[25,26]$, we predicted that miR494 may target survivin to increase the TRAIL sensitivity in gastric cancer. To confirm the miR-494/survivin axis in gastric cancer, we performed western blot analysis in BGC-823 and MGC-803 cells. We found that transfection with miR-494 obviously inhibited the expression level of survivin (Fig. 4C). Furthermore, the results of luciferase reporter assays showed that co-transfection with miR-494 mimics significantly decreased the luciferase activities of pMIR-reporter contained wild type survivin 3' UTR but not the mutant pMIR-reporter or the empty one (Fig. 4D). Taken together, we proved that miR-494 targeted survivin in gastric cancer.

Fig. 4. MiR-494 targets survivin in gastric cancer. A: Putative binding site paired with miR-494 at the 3' UTR of survivin mRNA. B: Western blot analysis was performed to evaluate the expression level of survivin in normal tissues, BGC-823 and MGC-803 cell lines. C: Western blot analysis was performed to evaluate the effect of miR-494 (50 $\mathrm{pmol} / \mathrm{ml}$ ) and TRAIL (50 ng/ml) on regulating the expression level of survivin in BGC823 and MGC-803 cells. D: BGC-823 and MGC-803 cells were co-transfected with recombinant pMIR-firefly luciferase reporters, pRL-TK renilla plasmid and miR-494 mimics by using Lipofectamine 2000. $48 \mathrm{~h}$ later, luciferase activities were measured by using Dual Luciferase Assay System according to the manufacturer's instruction.

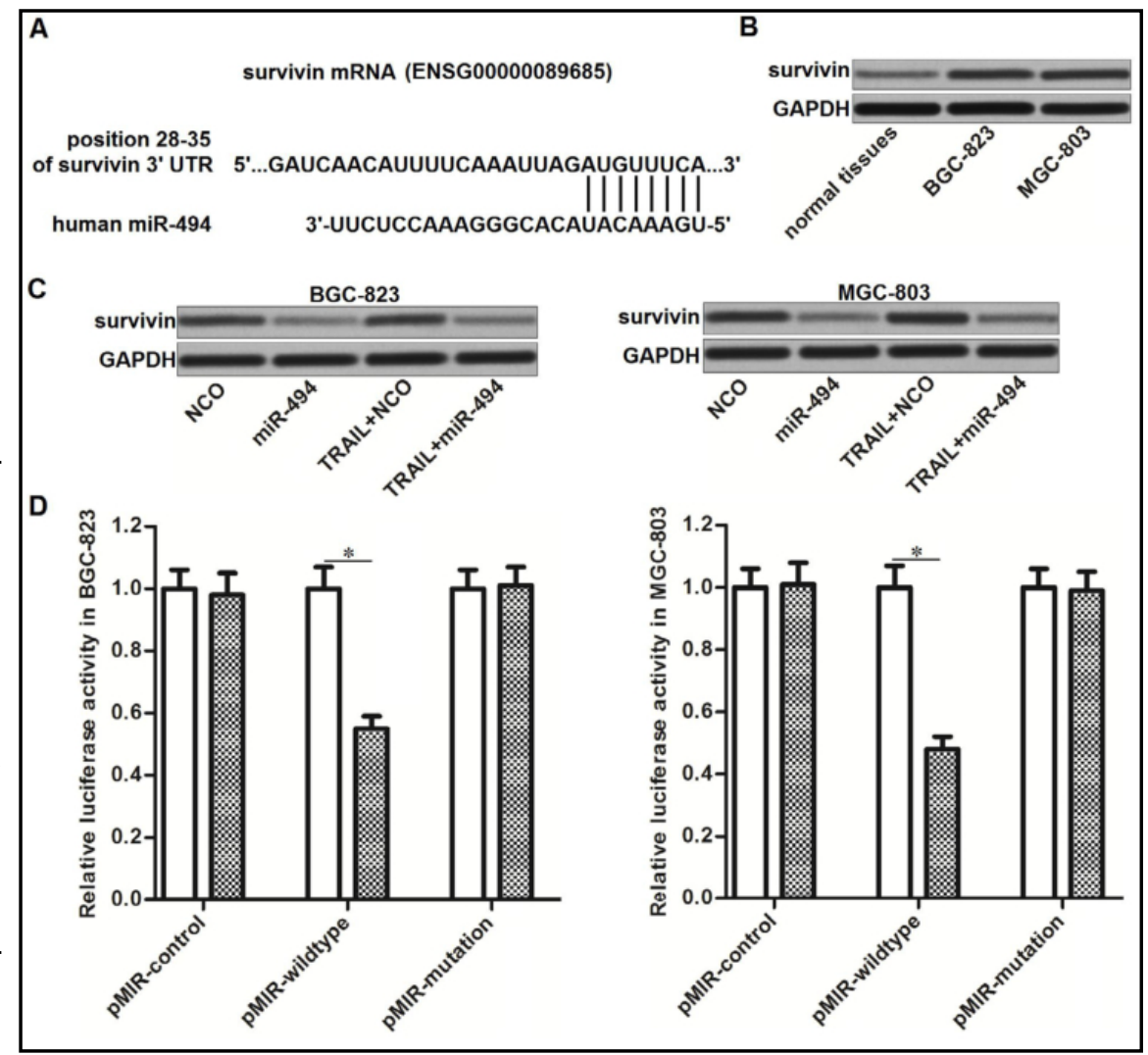




\section{Cellular Physiology Cell Physiol Biochem 2018;51:2212-2223 \begin{tabular}{ll|l} 
and Biochemistry & DOl: 10.1159/000495867 & $\begin{array}{l}\text { O 2018 The Author(s). Published by S. Karger AG, Basel } \\
\text { www.karger.com/cpb }\end{array}$
\end{tabular}

miR-494 sensitizes gastric cancer to TRAIL through inhibition of survivin

To investigate whether the sensitization of miR-494 on TRAIL-induced cytotoxicity to gastric cancer was mediated by survivin pathway, we performed loss-of-function and gainof-function experiments on survivin by using its specific siRNA and overexpression vector, respectively. We observed that transfection with survivin siRNA suppressed the survivin expression, whereas treatment with survivin vector increased the expression of survivin by force (Fig. 5A). Results of cell viability assays showed that the sensitization of miR-494 on TRAIL-induced cytotoxicity against gastric cancer was abolished due to the survivin plasmid co-transfection. On the other hand, knockdown of survivin directly by using survivin siRNA significantly enhanced the TRAIL-induced cell death of BGC-823 and MGC-803, similarly with miR-494 (Fig. 5B). Intuitively, miR-494 decreased the IC50 of TRAIL to BGC-823 and MGC-803 gastric cancer cells, whereas survivin plasmid inhibited the effect of miR-494 (Fig. 5C). As YM-155 has been proved to be a inhibitor of survivin [27], we co-treated the gastric cancer cells with YM-155 and TRAIL to evaluate the role of survivin in TRAIL-induced cytotoxicity. Our results showed that YM-155 significantly enhanced the TRAIL-induced cell death in BGC-823 and MGC-803 cells, similarly with miR-494 (Fig. 5D). Taken together, we demonstrated that the synergistic effect of miR-494 on sensitizing the TRAIL-induced cytotoxicity was dependent on the suppression of survivin in gastric cancer.

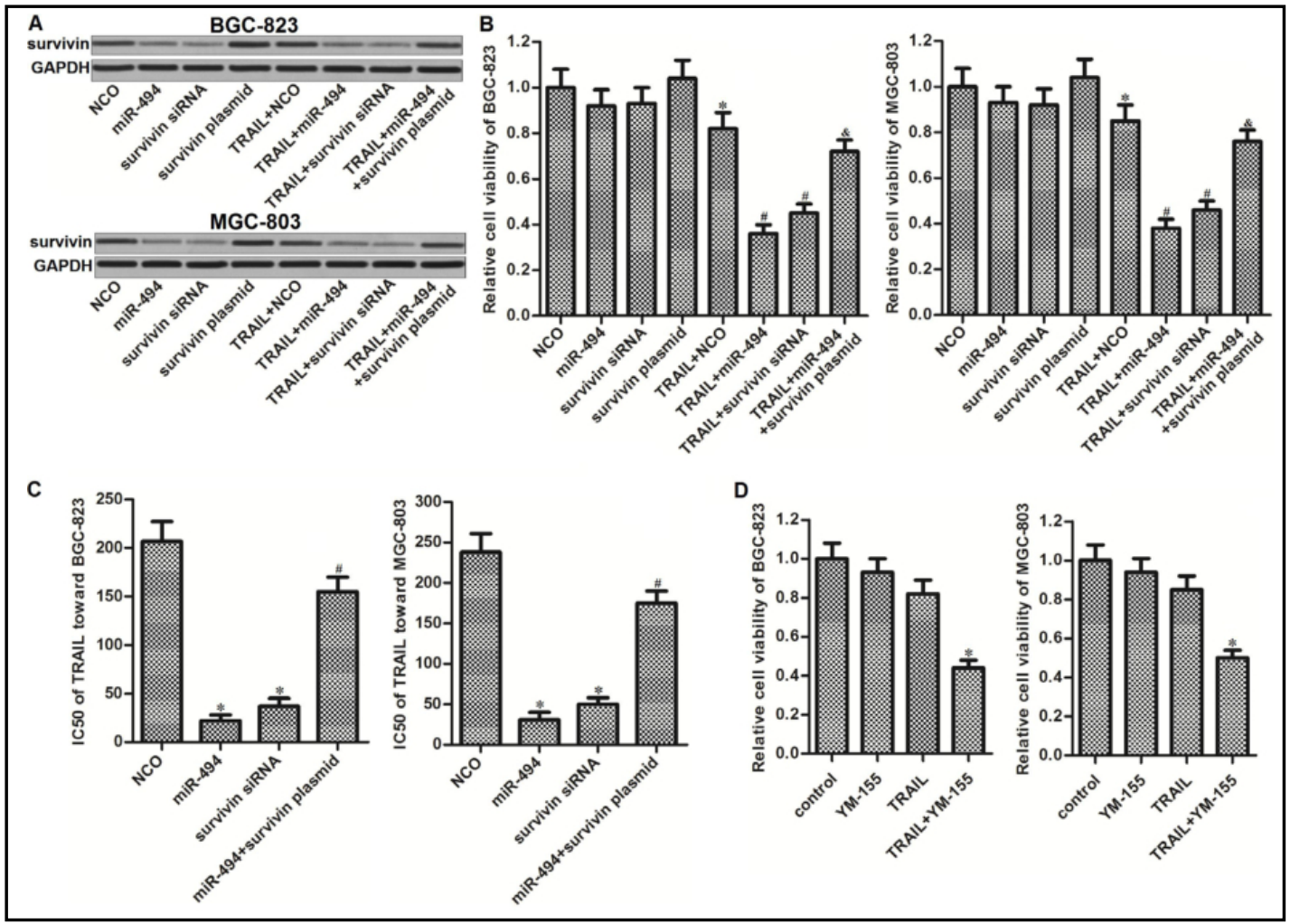

Fig. 5. MiR-494 sensitizes TRAIL-induced cytotoxicity against gastric cancer through suppression of survivin. A: Transfection efficiency of miR-494 mimics, survivin siRNA and survivin plasmid on regulating the survivin expression was detected by western blot analysis. B: Effect of miR-494 mimics, survivin siRNA and survivin plasmid on regulating the cytotoxicity of TRAIL (50 ng/ml) against BGC-823 and MGC-803 cells. ${ }^{*} \mathrm{P}<0.05$ vs. NCO group. ${ }^{*} \mathrm{P}<0.05$ vs. TRAIL + NCO group. ${ }^{\circledR} \mathrm{P}<0.05$ vs. TRAIL + miR-494 group. C: Effect of miR-494 mimics, survivin siRNA and survivin plasmid on regulating the IC50 of TRAIL toward BGC-823 and MGC-803 cells. ${ }^{*} \mathrm{P}<0.05$ vs. NCO group. ${ }^{\#} \mathrm{P}<0.05$ vs. miR-494 group. D: Effect of $\mathrm{YM}-155$ ( $\left.2 \mathrm{nM}\right)$ on regulating the cytotoxicity of TRAIL ( $50 \mathrm{ng} / \mathrm{ml}$ ) against BGC-823 and MGC-803 cells. ${ }^{*} \mathrm{P}<0.05$ vs. TRAIL group. 


\section{\begin{tabular}{lll} 
Cellular Physiology & \multicolumn{1}{c}{ Cell Physiol Biochem 2018;51:2212-2223 } \\
DOl: 10.1159/000495867 & (0 2018 The Author(s). Published by S. Karger AG, Basel
\end{tabular}

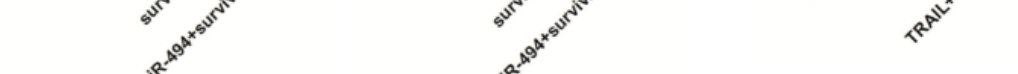

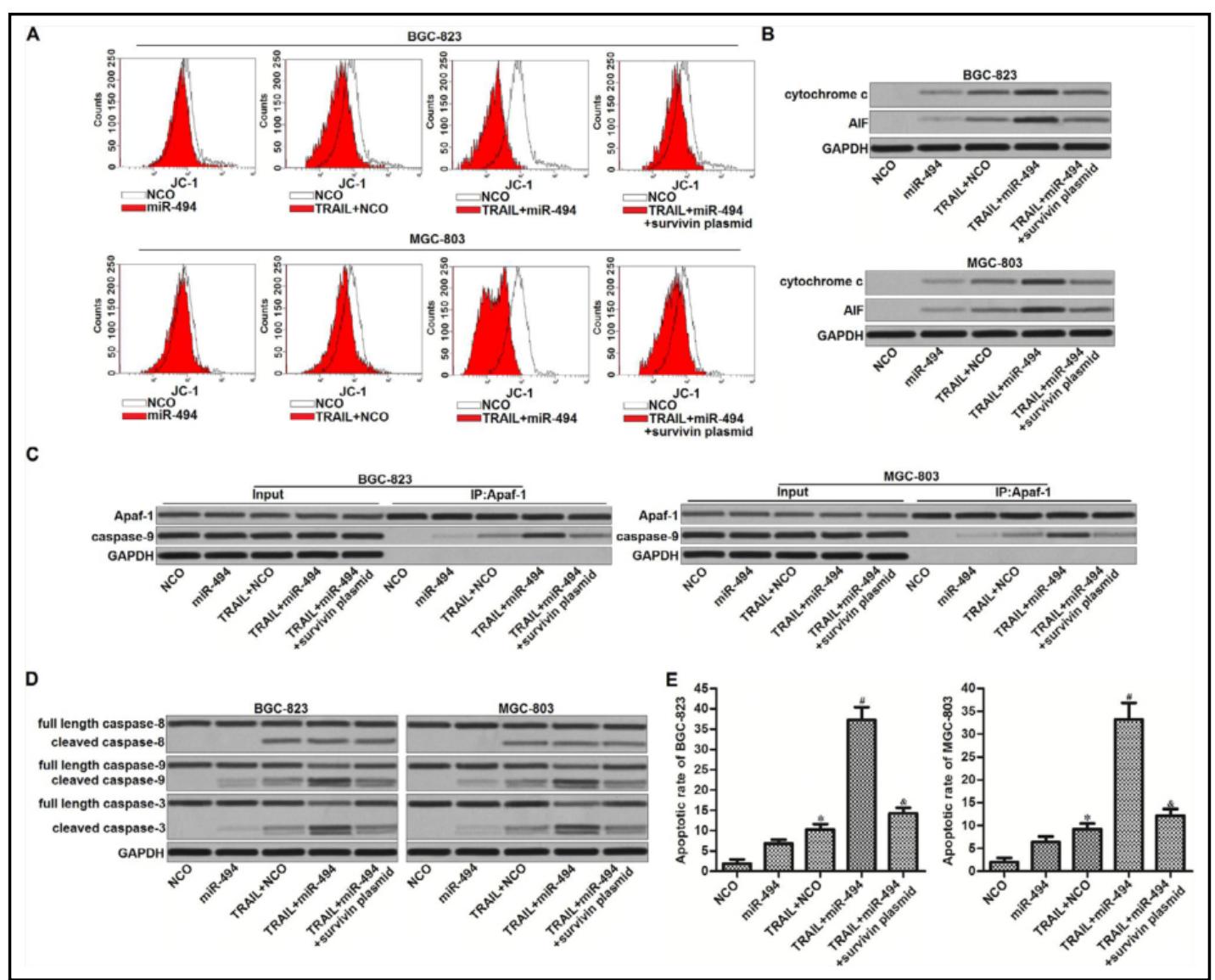

Fig. 6. Role of miR-494/survivin axis in regulating the TRAIL-induced mitochondrial apoptosis in gastric cancer. A: After treatment with miR-494, survivin plasmid and TRAIL (50 ng/ml) in BGC-823 and MGC-803 cells, mitochondrial membrane potential was detected by flow cytometry. B: After treatment with miR-494, survivin plasmid and TRAIL (50 ng/ml) in BGC-823 and MGC-803 cells, mitochondria was separated from cytoplasm by using Mitochondria / Cytosol Fraction Kit. Western blot analysis was performed to detect the cytochrome $\mathrm{c}$ and AIF in the remaining cytoplasm fraction. C: After treatment with miR-494, survivin plasmid and TRAIL (50 ng/ml) in BGC-823 and MGC-803 cells, interaction with Apaf- 1 and caspase-8 was evaluated by immunoprecipitation and western blot analysis. D: After treatment with miR-494, survivin plasmid and TRAIL (50 ng/ml) in BGC-823 and MGC-803 cells, cleavage of caspase-8, caspase- 9 and caspase- 3 was evaluated by western blot analysis. E: After treatment with miR-494, survivin plasmid and TRAIL ( $50 \mathrm{ng} / \mathrm{ml})$, apoptotic rate of BGC-823 and MGC-803 cells was measured by using flow cytometry analysis. ${ }^{*} \mathrm{P}<0.05$ vs. NCO group. ${ }^{*} \mathrm{P}<0.05$ vs. TRAIL + NCO group. ${ }^{\circledR} \mathrm{P}<0.05$ vs. TRAIL + miR-494 group.

miR-494/survivin axis regulates TRAIL-induced mitochondrial apoptosis in gastric cancer

As overexpression of survivin has been reported to be responsible for inhibition of mitochondrial apoptosis [27], we next investigated the effect of miR-494 on regulating the TRAIL-induced mitochondrial apoptosis pathway. Results of flow cytometry showed that the TRAIL-induced decrease of mitochondrial membrane potential can be expanded by miR- 494 . However, co-transfection with survivin plasmid obviously inhibited the effect of miR-494 (Fig. 6A). Results of western blot analysis showed that co-treatment with miR-494 obviously promoted the release of cytochrome $\mathrm{c}$ and AIF from mitochondria into cytoplasm (Fig. 6B). Furthermore, we observed obvious interaction with Apaf- 1 and caspase- 9 in the TRAIL and miR-494-cotreated BGC-823 and MGC-803 cells (Fig. 6C) in the presence of cytochrome c [28]. As the results, although miR-494 failed to promote the activation of caspase- 8 which is the substrate of TRAIL-DR4/DR5 complex [11], it increased the activation of caspase-9 and caspase-3 in the TRAIL-treated gastric cancer cells (Fig. 6D). We then found that miR- 
Fig. 7. MiR-494 A

enhances anti-tumor effect of TRAIL on gastric cancer in vivo. A: BGC-823 cells transduced with empty lentiviral vector or lentiviral vector carrying miR494 sequence were subcutan e ous ly injected into the of nude mice $(\mathrm{BALB} / \mathrm{c}$, $\mathrm{nu} / \mathrm{nu}, \quad 17-22 \mathrm{~g}$, 4-week-old, female, $\mathrm{n}=28, \quad 7$ mice for each group). After xenografts reached $0.5 \mathrm{~cm}$ in diameter, animals were treated
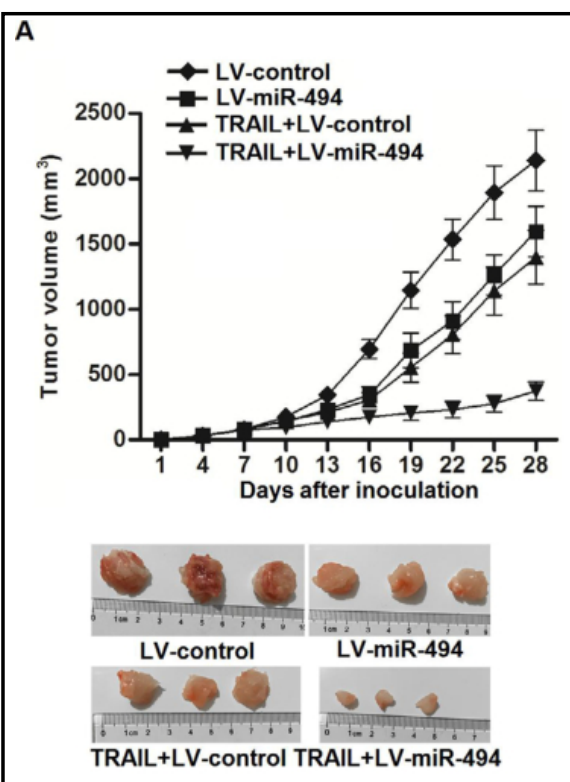

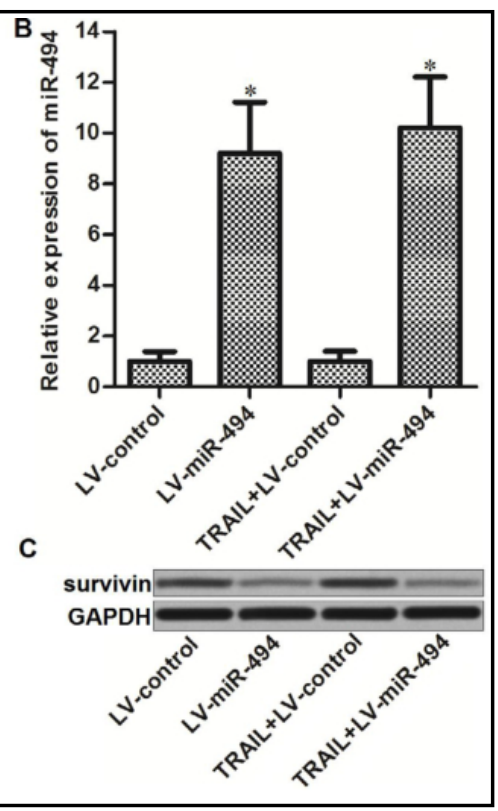
with TRAIL i.p. twice a week $(50 \mu \mathrm{g} / \mathrm{kg})$ until the mice were killed 28 days post-injection. B: QRT-PCR analysis was performed to evaluate the expression of miR-494 in the resected tumors from the mice. ${ }^{*} \mathrm{P}<0.05 \mathrm{vs}$. LV-control group. C: Western blot analysis was performed to evaluate the expression of survivin in the resected tumors from the mice.

494 was able to expand the TRAIL-dependent apoptosis in BGC-823 and MGC-803 cells, whereas the effect of miR-494 was inhibited by survivin plasmid (Fig. 6E). Token together, we demonstrated that overexpression of miR-494 was able to enhance the TRAIL-induced mitochondrial apoptosis in gastric cancer through suppression of survivin.

miR-494 enhances the anti-tumor effect of TRAIL on gastric cancer in vivo

To investigate the role of miR-494 in TRAIL treatment in vivo, miR-494-overexpressed or control BGC-823 cells were inoculated to the nude mice. Under the equal dose of TRAIL treatment, we observed that growth of miR-494-overexpressed gastric cancer tumors were significantly slower than the control tumors (Fig. 7A). Subsequently, we purified the tumor tissues resected from the mice. Results of qRT-PCR assays showed that LV-miR-494transfected BGC-823 tumors expressed significantly higher levels of miR-494 compared to the control tumors (Fig. 7B), whereas the expression levels of survivin were obviously suppressed in these miR-494-overexpressed BGC-823 tumors (Fig. 7C). Token together, we demonstrated that enforced expression of miR-494 inhibited the survivin in gastric cancer cells in vivo. Moreover, the in vivo anti-tumor effect of TRAIL on gastric cancer can be enhanced by the miR-494/survivin axis.

\section{Discussion}

Although TRAIL is an effective and low-toxic anti-tumor drug used for treatment of cancers such as colorectal cancer and non-small cell lung cancer, gastric cancer has been reported to show insensitive to TRAIL $[29,30]$. Therefore, we are supposed to sensitize the gastric cancer cells to TRAIL treatment. Dysregulation of miRNA expression profile has been proved to be responsible for drug resistance. Among these miRNAs, miR-494 is usually downregulated in cancers. Furthermore, it has been found that miR-494 acts as a potential tumor suppressor, because miR-494 inhibits progression of oral cancer, breast cancer and 


\section{Cellular Physiology Cell Physiol Biochem 2018;51:2212-2223 \begin{tabular}{ll|l} 
and Biochemistry & $\begin{array}{l}\text { DOl: 10.1159/000495867 } \\
\text { Published online: } / \text { December } 2018\end{array}$ & $\begin{array}{l}\text { O 2018 The Author(s). Published by S. Karger AG, Basel } \\
\text { www.karger.com/cpb }\end{array}$ \\
\cline { 2 - 3 }
\end{tabular} \\ Xu et al.: miR-494 Sensitizes Gastric Cancer to TRAIL}

ovarian cancer [31-33]. However, the role of miR-494 in regulating the TRAIL sensitivity in gastric cancer is still unclear.

In the present study, we found significant downregulation of miR-494 in gastric cancer patients' tumor tissues and in vitro gastric cancer cell lines. To investigate the role of miR494 in TRAIL sensitivity in gastric cancer, we restored the miR-494 expression in gastric cancer cell lines. We found that enforced expression of miR-494 significantly enhanced the anti-tumor effect of TRAIL on gastric cancer in vitro and in vivo, despite the miR-494 single treatment exhibited low cytotoxicity to gastric cancer. We demonstrated the effect of miR494 on sensitizing the TRAIL-induced cytotoxicity against gastric cancer.

Survivin is an anti-apoptotic protein, belonged to the inhibitor of apoptosis protein (IAP) family [24]. Studies have reported that survivin is usually overexpressed in multiple cancers, such as breast cancer, cervical cancer, bladder cancer and gliomas. Overexpression of survivin indicates poor prognosis and cancer progression [34-37]. As an anti-apoptotic protein, survivin inhibits mitochondrial cytochrome c release and activation of caspase- 9 and caspase-3 $[38,39]$. Therefore, overexpression of survivin can decrease the drug sensitivity of cancer cells.

In TRAIL signaling pathway, TRAIL binds to DR4 and DR5 to form the DISC. Subsequently, caspase-8 is triggered followed by induction of mitochondria collapse [9-11]. As the downstream incidence of mitochondria collapse, some mitochondria-derived apoptosis inducers such as cytochrome $c$ and AIF were released into the cytoplasm [40, 41]. As the results, caspase- 9 and its substrate caspase- 3 was triggered before occurrence of apoptosis.

In this study, we found that miR-494 failed to influence the distribution of DR4 and DR5, and activation of caspase-8 in gastric cancer cells. It suggested that miR-494 targeted some other factor in the TRAIL-dependent apoptosis pathway to enhance the anti-tumor effect of TRAIL. We then found that expression level of survivin can be inhibited by miR494 treatment. Moreover, we discovered the key role of miR-494/survivin axis in regulating the TRAIL-dependent mitochondrial apoptosis, because miR-494 co-treatment was found to promote the TRAIL-induced decrease of mitochondrial membrane potential, release of cytochrome c and AIF, interaction with Apaf- 1 and caspase-9, activation of caspase- 9 and caspase-3, and occurrence of apoptosis.

\section{Conclusion}

We found that gastric cancer cells expressed low level of miR-494. Moreover, we demonstrated that enforced expression of miR-494 can improve the anti-tumor effect of TRAIL on gastric cancer in vitro and in vivo. These findings provide an attractive strategy for efficient treatment of TRAIL on gastric cancer.

\section{Disclosure Statement}

The authors declare to have no competing interests.

\section{References}

\footnotetext{
1 Siegel R, Naishadham D, Jemal A: Cancer statistics, 2013. CA Cancer J Clin 2013;63:11-30.

- Kamangar F, Dores GM, Anderson WF: Patterns of cancer incidence, mortality, and prevalence across five continents: defining priorities to reduce cancer disparities in different geographic regions of the world. Clin Oncol 2006;24:2137-2150.

-3 Bornschein J, Malfertheiner P: Gastric carcinogenesis. Langenbecks Arch Surg 2011;396:729-742.
} 


\section{Cellular Physiology Cell Physiol Biochem 2018;51:2212-2223 \begin{tabular}{l|l|l} 
and Biochemistry Published onlIne: 7 December 2018 & $\begin{array}{l}\text { (c) } 2018 \text { The Author(s). Published by S. Karger AG, Basel } \\
\text { www.karger.com/cpb }\end{array}$ \\
\hline
\end{tabular}}

Xu et al.: miR-494 Sensitizes Gastric Cancer to TRAIL

4 Orditura M, Galizia G, Sforza V, Gambardella V, Fabozzi A, Laterza MM, Andreozzi F, Ventriglia J, Savastano B, Mabilia A, Lieto E, Ciardiello F, De Vita F: Treatment of gastric cancer. World J Gastroenterol 2014;20:16351649.

5 Niccolai E, Taddei A, Prisco D, Amedei A: Gastric cancer and the epoch of immunotherapy approaches. World J Gastroenterol 2015;21:5778-5793.

6 Choi AH, Kim J, Chao J: Perioperative chemotherapy for resectable gastric cancer: MAGIC and beyond. World J Gastroenterol 2015;21:7343-7348.

7 Shi WJ, Gao JB: Molecular mechanisms of chemoresistance in gastric cancer. World J Gastrointest Oncol 2016;8:673-681.

-8 An Y, Zhang Z, Shang Y, Jiang X, Dong J, Yu P, Nie Y, Zhao Q: miR-23b-3p regulates the chemoresistance of gastric cancer cells by targeting ATG12 and HMGB2. Cell Death Dis 2015;6:e1766.

-9 Enari M, Talanian RV, Wong WW, Nagata S: Sequential activation of ICE-like and CPP32-like proteases during Fas-mediated apoptosis. Nature 1996;380:723-726.

10 Joshi P, Jeon YJ, Laganà A, Middleton J, Secchiero P, Garofalo M, Croce CM: MicroRNA-148a reduces tumorigenesis and increases TRAIL-induced apoptosis in NSCLC. Proc Natl Acad Sci U S A 2015;112:86508655.

11 Xu C, Shi L, Chen W, Fang P, Li J, Jin L, Pan Z, Pan C: MiR-106b inhibitors sensitize TRAIL-induced apoptosis in hepatocellular carcinoma through increase of death receptor 4. Oncotarget 2017;8:41921-41931.

12 Walczak H, Miller RE, Ariail K, Gliniak B, Griffith TS, Kubin M, Chin W, Jones J, Woodward A, Le T, Smith C, Smolak P, Goodwin RG, Rauch CT, Schuh JC, Lynch DH: Tumoricidal activity of tumor necrosis factor-related apoptosis-inducing ligand in vivo. Nat Med 1999;5:157-163.

13 Trarbach T, Moehler M, Heinemann V, Köhne CH, Przyborek M, Schulz C, Sneller V, Gallant G, Kanzler S: Phase II trial of mapatumumab, a fully human agonistic monoclonal antibody that targets and activates the tumour necrosis factor apoptosis-inducing ligand receptor-1 (TRAIL-R1), in patients with refractory colorectal cancer. Br J Cancer 2010;102:506-512.

-14 Xu L, Qu X, Luo Y, Zhang Y, Liu J, Qu J, Zhang L, Liu Y: Epirubicin enhances TRAIL-induced apoptosis in gastric cancer cells by promoting death receptor clustering in lipid rafts. Mol Med Rep 2011;4:407-411.

-15 Belkhiri A, Zhu S, Chen Z, Soutto M, El-Rifai W: Resistance to TRAIL is mediated by DARPP-32 in gastric cancer. Clin. Cancer Res 2012;18:3889-3900.

16 Bartel DP: MicroRNAs: genomics, biogenesis, mechanism, and function. Cell 2004;116:281-297.

17 Bartel DP: MicroRNAs: target recognition and regulatory functions. Cell 2009;136:215-233.

18 Macfarlane LA, Murphy PR: MicroRNA: Biogenesis, Function and Role in Cancer. Curr Genomics 2010;11:537-561.

19 Di Leva G, Garofalo M, Croce CM: MicroRNAs in cancer. Annu Rev Pathol 2014;9:287-314.

20 Zhong X, Coukos G, Zhang L: miRNAs in human cancer. Methods Mol Biol 2012;822:295-306.

21 Zhang W, Zhou J, Zhu X, Yuan H: MiR-126 reverses drug resistance to TRAIL through inhibiting the expression of c-FLIP in cervical cancer. Gene 2017;627:420-427.

-22 Sun X, Li Y, Zheng M, Zuo W, Zheng W: MicroRNA-223 Increases the Sensitivity of Triple-Negative Breast Cancer Stem Cells to TRAIL-Induced Apoptosis by Targeting HAX-1. PLoS One 2016;11:e0162754.

-23 Livak KJ, Schmittgen TD: Analysis of relative gene expression data using real-time quantitative PCR and the 2(-Delta Delta C(T)) Method. Methods 2001;25:402-408.

24 Salvesen GS and Duckett CS: IAP proteins: blocking the road to death's door. Nat Rev Mol Cell Biol 2002;3:401-410.

25 Hwang JS, Lee HC, Oh SC, Lee DH, Kwon KH: Shogaol overcomes TRAIL resistance in colon cancer cells via inhibiting of survivin. Tumour Biol 2015;36:8819-8829.

-26 Park SH, Park SJ, Kim JO, Shin JH, Kim ES, Jo YK, Kim JS, Park SJ, Jin DH, Hwang JJ, Lee SJ, Jeong SY, Lee C, Kim I, Cho DH: Down-Regulation of Survivin by Nemadipine-A Sensitizes Cancer Cells to TRAIL-Induced Apoptosis. Biomol Ther (Seoul) 2013;21:29-34.

27 Premkumar DR, Jane EP, Foster KA, Pollack IF: Survivin inhibitor YM-155 sensitizes tumor necrosis factorrelated apoptosis-inducing ligand-resistant glioma cells to apoptosis through Mcl-1 downregulation and by engaging the mitochondrial death pathway. J Pharmacol Exp Ther 2013;346:201-210.

-28 Jiang X, Wang X: Cytochrome c promotes caspase-9 activation by inducing nucleotide binding to Apaf- 1 . J Biol Chem 2000;275:31199-31203. 


\section{Cellular Physiology Cell Physiol Biochem 2018:51:2212-2223 \begin{tabular}{l|l|l|l} 
DOI: 10.1159/000495867 & $\begin{array}{l}\text { O 2018 The Author(s). Published by S. Karger AG, Basel } \\
\text { www.karger.com/cpb }\end{array}$
\end{tabular} \\ Xu et al.: miR-494 Sensitizes Gastric Cancer to TRAIL}

29 Trarbach T, Moehler M, Heinemann V, Köhne CH, Przyborek M, Schulz C, Sneller V, Gallant G, Kanzler, S: Phase II trial of mapatumumab, a fully human agonistic monoclonal antibody that targets and activates the tumour necrosis factor apoptosis-inducing ligand receptor-1 (TRAIL-R1), in patients with refractory colorectal cancer. Br. J. Cancer 2010;102:506-512.

30 Greco FA, Bonomi P, Crawford J, Kelly K, Oh Y, Halpern W, Lo L, Gallant G, Klein J: Phase 2 study of mapatumumab, a fully human agonistic monoclonal antibody which targets and activates the TRAIL receptor-1, in patients with advanced non-small cell lung cancer. Lung cancer 2008;61:82-90.

-31 Libório-Kimura TN, Jung HM, Chan EK: miR-494 represses HOXA10 expression and inhibits cell proliferation in oral cancer. Oral Oncol 2015;51:151-157.

-32 Song L, Liu D, Wang B, He J, Zhang S, Dai Z, Ma X, Wang X: miR-494 suppresses the progression of breast cancer in vitro by targeting CXCR4 through the Wnt/ $\beta$-catenin signaling pathway. Oncol Rep 2015;34:525531.

33 Zhao X, Zhou Y, Chen YU, Yu F: miR-494 inhibits ovarian cancer cell proliferation and promotes apoptosis by targeting FGFR2. Oncol Lett 2016;11:4245-4251.

-34 Li Y, Ma X, Wu X, Liu X, Liu L: Prognostic significance of survivin in breast cancer: meta-analysis. Breast J 2014;20:514-524.

35 Cao XQ Lu HS, Zhang L, Chen LL, Gan MF: MEKK3 and survivin expression in cervical cancer: association with clinicopathological factors and prognosis. Asian Pac J Cancer Prev 2014;15:5271-5276.

-36 Abd El-Hakim TF, El-Shafie MK, Abdou AG, Azmy RM, El-Naidany SS, Badr El-Din MO: Value of urinary survivin as a diagnostic marker in bladder cancer. Anal Quant Cytopathol Histpathol 2014;36:121-127.

37 Chakravarti A, Noll E, Black PM, Finkelstein DF, Finkelstein DM, Dyson NJ, Loeffler JS: Quantitatively determined survivin expression levels are of prognostic value in human gliomas. J Clin Oncol 2002;20:1063-1068.

-38 Shin S, Sung BJ, Cho YS, Kim HJ, Ha NC, Hwang JI, Chung CW, Jung YK, Oh BH: An anti-apoptotic protein human survivin is a direct inhibitor of caspase-3 and -7. Biochemistry 2001;40:1117-1123.

39 Minoda M, Kawamoto T, Ueha T, Kamata E, Morishita M, Harada R, Toda M, Onishi Y, Hara H, Kurosaka M, Akisue T: Antitumor effect of YM155, a novel small-molecule survivin suppressant, via mitochondrial apoptosis in human MFH/UPS. Int J Oncol 2015;47:891-899.

40 Fehlberg S, Gregel CM, Göke A, Göke R: Bisphenol A diglycidyl ether-induced apoptosis involves Bax/Biddependent mitochondrial release of apoptosis-inducing factor (AIF), cytochrome c and Smac/DIABLO. Br J Pharmacol 2003;139:495-500.

41 Yel L, Brown LE, Su K, Gollapudi S, Gupta S: Thimerosal induces neuronal cell apoptosis by causing cytochrome c and apoptosis-inducing factor release from mitochondria. Int J Mol Med 2005;16:971-977. 